\title{
Cultural Dimensions as Correlates of Favoritism and the Mediating Role of Trust
}

\author{
Hohjin $\operatorname{Im}^{1} \&$ Chuansheng Chen ${ }^{1}$ \\ ${ }^{1}$ University of California, Irvine
}

\begin{abstract}
Purpose: This study sought to examine the relation of cultural practices and values with favoritism and nepotism/cronyism. Additionally, this study's purpose was also to examine how trust mediates the relation between culture and favoritism. Design/Methodology/Approach: Correlations were used for exploratory investigation into the bivariate relations between culture and favoritism and nepotism/cronyism across 97 cultures. Hierarchical linear regression analyses were then conducted to examine the cultural correlates of favoritism and nepotism/cronyism holding all other variables constant. Lastly, partial least squares structural equation modeling was used to examine the mediating role of societal levels of trust. Findings: Bivariate correlations show that collectivism, familism, uncertainty avoidance, and power distance are positive correlates of both favoritism and nepotism/cronyism. Institutional collectivism, future orientation, and trust, on the other hand, were negative correlates of favoritism and nepotism/cronyism. Uncertainty avoidance and trust were key correlates of favoritism while familism and future orientation were key correlates of nepotism/cronyism. Trust fully mediated the relation between culture and favoritism but did not mediate the relation between culture and nepotism/cronyism. Originality/Value: This study adds to the current body of literature on culture and favoritism. Notably, the findings regarding different key cultural correlates with respect to favoritism and nepotism/cronyism provide valuable implications for expanding our understanding of the psychological and social nuances of favoritism. Specifically, favoritism in transactions and interactions with those not bound by social commitment relationships may be explained by beliefs while interactions with those with social relationships (e.g., family and friends) may be explained by preferences.
\end{abstract}

Keywords: Favoritism, Nepotism, Cronyism; Culture, Uncertainty Avoidance, Collectivism, Familism; Trust

For managers, directors, and executives, ethical dilemmas are common, but necessary, components of the daily demands of their profession. One prominent and rampant ethical dilemma is the issue of favoritism, i.e., giving preferential treatment to select individuals or groups for their relationships rather than for objective or meritbased reasons. One of the most common forms of favoritism is the act of hiring an otherwise unqualified family member (i.e., nepotism) or friend (i.e., cronyism) over a qualified stranger. Favoritism can manifest in various aspects of one's job, such as job advancement (Barnett \& McCormick, 2004) or publication opportunities (Medoff, 2003), among others. In recent years, various exposés of unethical conduct and corruption by political and business leaders quickly cascaded through news media and caught the ire of the frustrated public, fueled by the already turbulent state of political and economic affairs. Favoritism was no exception and was the subject of headline news across the globe; in South Korea, the KEB Hana Bank's favoritism in hiring practices came under public scrutiny (Yonhap News, 2018); political rivals and news media lambasted current United States President, Donald Trump's, decision to appoint close individuals to high advisory roles despite their questionable track record of relevant experiences (e.g., Abramson, 2018; Erickson, 2017; Holden, 2018); Argentina President Mauricio 
Macri banned the employment of family members in government positions to combat the traditional patronage system (BBC News, 2018).

The pervasiveness of favoritism across cultures has drawn the attention of various scholars who have offered propositions for the antecedents underlying the mechanisms of nepotism and cronyism as well as their consequences (Khatri, 2009; Khatri \& Tsang, 2003; Wated \& Sanchez, 2012). While favoritism has been a popular topic of inquiry among scholars, the mechanisms underlying it remains not well understood (Everett, Faber, \& Crockett, 2015). To put it briefly, Everett and colleagues (2015) suggest that ingroup favoritism is driven by preferences and beliefs. In the context of ingroup favoritism, social preferences concern the ingroup's wellbeing over the outgroup and beliefs concern one's expectations about the ingroup and outgroup's future behaviors. Preferences for ingroup love-prosocial behavior towards the ingroup-and outgroup hate-antisocial behavior towards the outgroup-seem particularly susceptible to the influences of culture given that one's cognition and values are often molded by societal ideals. Indeed, unlike many other ethical transgressions that neatly align with the definition of corruption (i.e., the use of public power for personal benefit), such as embezzlement, favoritism remains a peculiar phenomenon in the sense that the extent to which it is regarded unethical can vary across cultures (e.g., Wated \& Sanchez, 2005, 2012). What is construed as favoritism in Western cultures may be a routine, regular, or natural process of establishing social connections in others. This difference in appraisal of favoritism behavior may perhaps be most palpable within societies where the cultural doctrine underpinning the informal rules of social interaction is rooted in collectivistic and interdependent ideals.

As firms work to engage in cross-border and international business, encountering culturally subjective dilemmas will certainly become more common. To facilitate effective and harmonious business interactions, it is imperative for scholars to have a foundational understanding of the cultural underpinnings of various ethical dilemmas that commonly arise within business settings. Because societal culture represents one of the broadest layers of culture, permeating down to its lower layers, such as organizational culture
(Hofstede, Hofstede, \& Minkov, 2010), our understanding of societal culture and its conduciveness to favoritism must first be developed. While many studies utilizing economic games have explored the decision processes of preferences and beliefs in ingroup favoritism (for review of these studies, see Everett et al., 2015), and cultural studies have inquired about specific cultural dimensions' affinity to favoritism (see citations given in the following subsections for each cultural dimension), no study has conceptually attempted to synthesize the two at the societal level utilizing all the cultural dimensions. To establish one of the first foundations for examining the links between favoritism and societal culture, the central mission of this paper is to examine how different dimensions of culture may underlie preferences for favoritism and nepotism/cronyism. In doing so, we seek to add to the current body of literature by integrating various theories of societal culture into a new model incorporating numerous aspects of culture.

\section{Culture and Its Relation to Favoritism}

In this study, we primarily rely on Hofstede's six Cultural Dimensions (Hofstede et al., 2010) and the Global Leadership \& Organizational Behavior Effectiveness's (GLOBE) Cultural Orientations (House, Hanges, Javidan, Dorfman, \& Gupta, 2004) to categorize culture. Each cultural dimension is covered in the following sections. Our review of the cultural dimensions is necessarily brief as the conceptual and theoretical literature on these dimensions is far too extensive to be adequately attended to in the span of a single paper's review of literature (for a more extensive review of these dimensions, see Hofstede et al., 2010 for the six cultural dimensions and House et al., 2004 for the nine cultural orientations). Thus, we focus on broad societal trends and their conceptual relation to favoritism. Both constructions of national cultures, however, are not without noteworthy faults; since their introduction to the academic sphere, both GLOBE's and Hofstede's methodology in defining and constructing their orientations and dimensions have been criticized by scholars ranging from methodology to theoretical validity (see criticisms raised in Blodgett, Bakir, \& Rose, 2008; Brewer \& Venaik, 2010; Hofstede, 2010; Hofstede et al., 2010; House et al., 2004; Maseland \& van Hoorn, 2009; Taras, Steel, \& Kirkman, 2010). To maintain ease of conceptual interpretation and clarity, hypotheses 
and results in this paper correspond with Hofstede's Cultural Dimensions and GLOBE's Cultural Practices. Interpretations of the results and limitations are given with these criticisms in mind.

\section{Collectivism and Individualism}

Individualism and collectivism represent opposite ends of the spectrum in a culture's valuation of the individual or group (Hofstede, 2011; Hofstede et al., 2010; Markus \& Kitayama, 1991). Individualistic cultures emphasize autonomy and independence whereas collectivistic cultures emphasize the collective group, value the maintenance of group cohesion, and seek to separate the in-group from the out-group (Hofstede, 2011; Markus \& Kitayama, 1991; Triandis, 1989, 2001). Some scholars, however, have challenged the binary conceptualization of the cultural construct. To address this issue, the GLOBE project separated the construct into two separate orientations: 1) institutional and 2) in-group collectivism. The prior construct stresses the importance of collective effort and goal-striving while the latter construct emphasizes familial values (House et al., 2004). Because the in-group collectivism orientation closely measures family values, the orientation is used in this study as a proxy for and addressed hereafter as familism.

As a result of its emphasis on ingroup wellbeing and interdependent values, collectivism has long been hypothesized by scholars as being conducive to behaviors favoring the ingroup. In several studies, collectivists tended to exhibit greater ingroup favoritism in the face of ingroup-outgroup performance dynamics (Chen, Brockner, \& Chen, 2002; Chen, Brockner, \& Katz, 1998). Further, Wang, Wu, Liu, Wu, and Han (2015) also found that collective priming induces greater empathy for ingroup members' pain or suffering. Indeed, such attention to ingroup members within the collective culture may shift one's preferences for ingroup wellbeing over the outgroup (Everett et al., 2015). In the same vein, because familism strongly emphasizes loyalty to one's family members, some scholars argued that it underlies favoritism for family (e.g., Banfield, 1958; Lapalombara, 1994) and the subjective norms associated with collectivist doctrines increase tolerance of nepotistic behavior (Wated \& Sanchez, 2012, 2015). Lapalombara (1994) suggests that adherence to bureaucratic cultural norms supersedes adherence to formal rules and laws, particularly for cultures in which said cultural norms define one's morality. In such cases, there may be greater ingroup love where the interests of the ingroup member becomes aligned with the interests of the acting agent (Tajfel \& Turner, 1979). Thus, the strong emphasis placed on the needs and wellbeing of ingroup members can take precedence over attending to formal rules or the wellbeing of outgroup members, ultimately resulting in the engagement in or expectation of behaviors akin to favoritism and ingroup bias.

Beyond empirical studies, ethnographic evidence of cultural norms related to favoritism are abundant; in traditionally collectivistic cultures, the adherence to social commitment relationships is rooted in both language and informal cultural rules. In China, favoritism is closely tied with the concept of guanxi, the establishment of a social connection between individuals; it is a normative cultural inauguration of basic social dynamics that is infused with the inherent notion of interpersonal and interorganizational relationships (Yang, 1994). The development of guanxi is implicit-contingent upon the mutual interests of both parties-and the expectations for reciprocal favors guide the maintenance of interpersonal cohesion (Yang, 1994). The concept of constructing and maintaining a close relationship, however, extends far beyond just the traditionally collectivistic East Asian cultural cluster. Concepts similar to guanxi are found in various other cultures that score high on collectivism, such as blat in Russia (Ledeneva, 1998, 2009) and wasta in Arab countries (Sidani \& Thornberry, 2013). Even in the absence of a specific term that denote the ritual of social interaction, culturally driven tendencies to give preferential treatment to close others may still manifest from related cultural values, as observed in Mexico (Boutilier, 2009). Such cultural norms may then permeate into organizational decisions. For instance, in a study of business leaders, Chinese and Japanese business leaders stated that they gave preference for the potential employee's network of relationships over their measurable skills (Martinsons \& Davison, 2007). Thus, given collectivism and familism's emphasis on relationships and affinity for ingroup favoritism, we posit the following hypothesis: 
Hypothesis 1: Collectivism/Familism will be positively related to perceptions of a) favoritism and b) nepotism/cronyism.

On the other hand, cultures high in institutional collectivism value group solidarity and loyalty, even at the expense of one's own individual goals. Thus, this prioritizes group cohesion over individual gain (House et al., 2004). Perhaps most contrasting from familism is that institutional collectivism prioritizes the gains of the larger collective group beyond just the small immediate in-group (e.g., family, close friends). Thus, institutional collectivism may correspond to lower rates of favoritism given that the goals of the larger group (e.g., organization's goal to maintain productivity) may be given priority over those of the individual (e.g., cater to the desires of a family member). Prior research examining group cohesion and performance have typically found positive correlation between the two, stemming from various causes including desiring longevity in membership or achieving interdependent goals (e.g., Casey-Campbell \& Martens, 2009; Evans \& Dion, 1991; Gully, Devine, \& Whitney, 1995). Thus, favoritism for an unqualified close in-group member over a qualified outgroup member may be regarded in a similar manner as threatening the goals of the overall group. For these reasons, we posit the following hypothesis:

Hypothesis 2: Institutional Collectivism will be negatively related to perceptions of a) favoritism and b) nepotism/cronyism.

\section{Uncertainty Avoidance}

Uncertainty avoidance is characterized by the extent to which a culture is intolerant of ambiguity and unstructured situations (Hofstede, 2011; Hofstede et al., 2010). Cultures that are high in uncertainty avoidance attempt to minimize ambiguity by implementing rules, regulations, and social norms of conduct that condemn deviant behavior. Hofstede (2011) characterizes high uncertainty avoidant cultures as needing clarity and structure. These cultures were also high in anxiety and may display more suspicion and aggression against others (Hofstede et al., 2010). Low uncertainty avoidant cultures, on the other hand, are more accepting of deviance and chaos.

While the rules and regulations may intuitively seem like deterrents of corruption, prior studies of uncertainty avoidance have shown positive relations between the cultural dimension and corruption (Davis \& Ruhe, 2003; Husted, 1999; Seleim \& Bontis, 2009; Yeganeh, 2014) and favoritism (Jeanquart-Barone \& Peluchette, 1999). Findings from the prior body of literature suggest that strict adherence to and observation of rules may not always pertain to prescribed anticorruption rules and laws. The positive relation between uncertainty avoidance and corruption may reflect stricter adherence to cultural values and norms that underlie behaviors like favoritism. In other words, if there is uncertainty regarding the outcome of any transaction, then there will be greater concern to protect oneself from exploitation (Yamagishi, Jin, \& Miller, 1998). Kollock (1994) provides an example of how uncertainty incentivizes particularistic bias; when attempting to purchase rice or rubber in Southeast Asian markets, the quality of rice is easy to inspect compared to rubber where the quality can only be properly assessed post-production. In other words, there's more uncertainty associated with rubber than rice and thus one may be more inclined to conduct business with trusted rubber vendors (to minimize risk of poor-quality rubber) whereas such risk avoidant inclinations are less necessary for rice vendors. Likewise, in business interactions, it is difficult to accurately assess the quality of a potential hire or business partner until after employment or business ventures. Indeed, studies that manipulated and induced greater uncertainty likewise led to greater formation of commitment relationships (Kollock, 1994; Yamagishi, Cook, \& Watabe, 1998; Yamagishi, Watabe, Hayashi, Takahashi, \& Yamagishi, 1996; Yamagishi, Yamagishi, Takahashi, Hayashi, \& Watabe, 1995). Thus, resorting to favoritism and opting to interact with familiar others may be a form of selfprotectionism by which one reduces or avoids the ambiguity associated with unknown others. For these reasons, we posit the following hypothesis:

Hypothesis 3: Uncertainty Avoidance will be positively related to perceptions of a) favoritism and b) nepotism/cronyism.

\section{Power Distance \& Hierarchy}

Power distance measures the culture's degree of acceptance of unequal distribution of power and tendency for subordinates and leaders to depend on each other (Hofstede, 2011; Hofstede et al., 2010). 
Unequal income distributions, autocratic style of governance, and hierarchical relationships between subordinates and leaders are some of the notable characteristics of high power distance cultures (Hofstede et al., 2010). Corruption is frequent in high power distance cultures (Davis \& Ruhe, 2003; Hofstede, 2011; Husted, 1999; Seleim \& Bontis, 2009; Yeganeh, 2014) and scholars have speculated that the high prevalence of paternalism and hierarchical relationships underlie some part of it (Akbar \& Vujić, 2014). Indeed, studies have documented that those in high-ranking positions tend to justify unethical behaviors, disregard observations of unethical practices (Kennedy \& Anderson, 2017), and maintain intentions for unethical behavior regardless of the presence of reward (Vriend, Jordan, \& Janssen, 2016). Further, Husted (1999) argues that decisions are driven by expectations of loyalty as opposed to merit. Similarly, Khatri and Tsang (2003) noted that valuation of loyalty was a key antecedent of cronyism. Thus, because those in command have considerable say in the decisions of the organization, with little confrontation from the subordinates below them, the paternalistic dynamic may promote unethical behaviors, like favoritism or nepotism, that would otherwise be met with criticism in the context of an egalitarian society striving for meritocracy. For these reasons, we posit the following hypothesis:

Hypothesis 4: Power Distance will be positively related to perceptions of a) favoritism and b) nepotism/cronyism.

\section{Long-Term Orientation and Future Orientation}

Long-Term Orientation and Future Orientation both measure the degree to which societies adapt and plan for the future (Hofstede, 2011; Hofstede et al., 2010; House et al., 2004). Societies high in long-term and future orientation tend to believe that success is derived from effort, save for the future, and make visionary plans for the future in spite of uncertainties. Those low in these dimensions tend to rely on traditions and routine patterns of behavior. In a correlational examination with corruption, Seleim and Bontis (2009) found that future orientation was related to lower corruption. Further, individuals who had a clearer sense of continuity between their current and future self were less likely to engage in unethical behaviors (Hershfield, Cohen, \& Thompson, 2012). Specific to favoritism, it may be reasoned that societies high in long-term and future orientation may denounce favoritism as interactions that deviate from meritocracy can subsequently result in lost production value. In other words, societies that tend to value future planning may hold greater credence to possible future harms that may derive from hiring otherwise unqualified individuals. For these reasons, we posit the following hypothesis:

Hypothesis 5: Long-Term/Future Orientation will be negatively related to perceptions of a) favoritism and b) nepotism/cronyism.

\section{Trust}

In light of the various cultural dimensions and orientations put forth by numerous scholars, one aspect of culture that often becomes muddied or presumably aggregated into other measurements of culture is the concept of general trust towards others. Trust has widely been studied in corruption literature but is often overlooked as an independent correlate of corruption. Specific to favoritism, trust has been documented as being instrumental in establishing nepotistic relationships (Dickson, Nieminen, \& Biermeier-Hanson, 2012) and is considered an integral component of conducting business in some cultures (Martinsons \& Davison, 2007).

In the case of collectivism and familism, greater duty to one's in-group may further polarize outgroups, thereby deteriorating trust of others outside one's immediate in-group (Allik \& Realo, 2004; Park, 2004; Realo, Allik, \& Greenfield, 2008). The low level of trust for outgroup others in collectivistic cultures, compared to individualistic cultures (Huff \& Kelley, 2003), may further incentivize the acquisition of known individuals in hiring processes, increasing rates of favoritism. It may be reasoned that one's suspicion of another's intention or motives derives from the said individual's dispositional distrust of others. If one is distrustful of an unknown other, then anxiety may be an inevitable outcome from the notion of interacting with an outgroup whose intentions remain ambiguous. Indeed, uncertainty avoidant cultures are documented as exhibiting high anxiety (Hofstede et al., 2010) and take preventative measures via rules and bureaucratic norms to avoid uncertain futures. Thus, societies high in uncertainty avoidance may seek to interact with 
trusted individuals in an attempt to safeguard oneself from uncertain outcomes, thereby further perpetuating the establishment of commitment relationships (Kollock, 1994; Yamagishi, Cook, et al., 1998; Yamagishi et al., 1996, 1995) and capitalizing on beliefs of expected reciprocity from the other party (Everett et al., 2015). Lastly, because high power distance and paternalism rely on personal loyalty (Husted, 1999; Khatri \& Tsang, 2003), these cultures may exhibit greater distrust of others. In other words, power distant cultures may be more skeptical of interacting with those whom such reciprocity is not guaranteed or likely. Thus, high power distance cultures may exhibit greater distrust for outgroup members, who may threaten the current status quo and engage in greater favoritism. For these reasons, we posit the following hypotheses:

Hypothesis 6: Trust will be negatively related to a) favoritism and b) nepotism/cronyism.

Hypothesis 7: Trust will mediate the relation between favoritism-related culture and perceptions of a) favoritism and b) nepotism/cronyism.

\section{Cultural Dimensions Unrelated to Favoritism}

While the cultural dimensions discussed in previous sections conceptually relate to favoritism, there are also some cultural dimensions that are conceptually ambiguous or weak in its relation to favoritism. For instance, Indulgence-Restraint measures the degree to which societies value satisfying their desires (indulgence) or controlling them (restraint). Typically, at the societal level, cultures high in restraint exhibit higher pessimism and social norms restrict or regulate one's indulgence in desires whereas those high in indulgence report greater positive perception of leisure-related activities, such as spending money or spending time with friends (Hofstede et al., 2010). However, indulgence and restraint orientations present little conceptual connections to greater perceptions of engagement in favoritism or nepotism/cronyism, as such behaviors are not typically considered gratification activities.

Similarly, little conceptual relation to favoritism can be derived from the cultural dimension of Masculinity-Femininity. Masculinity is the measurement of a culture's values among men and women, whereby masculine, relative to feminine, societies tend to be more assertive, competitive, tough, and have clear gender roles (Hofstede, 2011; Hofstede et al., 2010). While the dimension has been tied to corruption in prior literature (e.g., Husted, 1999), its conceptual relation to specifically favoritism is largely obscure; qualities in masculine cultures that would otherwise minimize favoritism, such as equity-based rewards (Hofstede et al., 2010), are not necessarily represented in the opposite femininity value. Likewise, the spin-off assertiveness orientation from GLOBE (House et al., 2004) presents a similar issue; assertive cultures are considered confrontational and aggressive-both qualities unrelated to engagement in or perception of favoritism. Further, the relevance of humane orientation, the degree of care and concern for others' well-being, and gender egalitarianism, the extent to which the society values equality among genders (House et al., 2004), with respect to favoritism are difficult to conceptualize as altruistic care for others and gender egalitarianism may be distantly related, but otherwise not relevant to favoritism. No theoretical or conceptual reasoning for either orientations can be made for hypothesizing that these dimensions will go in any direction for favoritism. Lastly, while performance orientation, the extent to which a society encourages performance achievement (House et al., 2004), may be highly related to favoritism, one item used in the construction of performance orientation measures the extent to which nepotism occurs within their workplace. Thus, to avoid the risk of a statistical false positive stemming from a partial measurement of favoritism (i.e., performance orientation) being correlated with the perception of favoritism, we offer bi-variate correlation results but otherwise do not interpret them or make any hypotheses about it.

Hypothesis 8: Favoritism will not be significantly related to a) Indulgence-Restraint, b) MasculinityFemininity, c) Humane Orientation, d) Gender Egalitarianism, and e) Assertiveness.

\section{The Current Study}

While many studies have attempted to examine the relation between culture and favoritism at the individual level (e.g., Jeanquart-Barone \& Peluchette, 1999; Wated \& Sanchez, 2005), our understanding of societal culture's affinity to favoritism remains not well understood. This paper 
seeks to add to the literature by examining broad categories of culture and its relation to favoritism. Further, despite the emphasis on trust found in much of the body of literature, no studies have examined whether cross-national relations between culture and favoritism are mediated by societal levels of trust. For these reasons, this current study utilizes cultural indices from Hofstede's National Cultural Dimensions (Hofstede et al., 2010) and GLOBE Project (House et al., 2004) as well as societal levels of trust from the World Values Survey (WVS) aggregate scores across all 6 waves (Inglehart et al., 2018). It is worth noting that the cultural variables used in this study stem from different timepoints of data collection, with Hofstede's measures from 1967-1973, GLOBE's measures from 1994-1997, and WVS measures from 1981-2014. While culture is not stable and subject to change, influenced by various factors, literature also suggests that cross-cultural differences are robust to generational effects and remain stable (Beugelsdijk \& Welzel, 2018; Hofstede et al., 2010). Thus, any unmeasured cultural change within the last few decades should pose no threat to the statistical validity of analyses used in this study. Nonetheless, recommendations for future studies are given in the Limitations section with cultural change in mind.

\section{Study 1: Relation Between Hofstede's Cultural Dimensions and Favoritism}

\section{Measures}

\section{Outcome Variables}

The outcome variables in this study are perceptions of 1) general favoritism and 2) nepotism/cronyism. The World Economic Forum publishes an annual report called the Global Competitiveness Report with individual country rankings based on the Global Competitiveness Index. The index is comprised of various pillars (i.e., categories) assessing different domains of economic, political, and organizational competitiveness. In this study, we utilize the 2017-2018 Global Competitiveness Report due to the availability of both the perceived favoritism and nepotism/cronyism variable (the perceived favoritism measure was excluded from the 2018 Global Competitiveness Report). Within the institutional pillar is an item inquiring about favoritism among government officials' interactions with firms. The item (1.07) asks, "In your country, to what extent do government officials show favoritism to well-connected firms and individuals when deciding upon policies and contracts?" The favoritism scale ranges from 1 (show favoritism to a great extent) to 7 (do not show favoritism at all). To measure nepotism/cronyism within the workplace, we utilized data from a single item (7.07) within the labor market efficiency pillar: "In your country, who holds senior management positions in companies?" The scale ranges from 1 (usually relatives or friends without regard to merit) to 7 (mostly professional managers chosen for merit and qualifications). For ease of statistical interpretation, both variables have been reversecoded in this study so that higher numbers indicate greater perception of favoritism. See Appendix Table B for data source.

\section{Predictor Variables}

Hofstede's Cultural Dimensions. All six Hofstede's cultural dimensions of 1) IndividualismCollectivism, 2) Power Distance, 3) Uncertainty Avoidance, 4) Masculinity-Femininity, 5) LongTerm Orientation, and 6) Indulgence-Restraint are included in this study. Each dimension was measured with 3-8 items (for detailed methodology and items, see Hofstede et al., 2010). The first dimension was reverse coded to indicate Collectivism scores to keep consistent with GLOBE measures of collectivism. Of the original 78 cultures for the first four dimensions, 68 cultures had overlapping data with the outcome variables and were included in this study. Of the 97 cultures for the last two dimensions, 85 had overlapping data and were included in this study. See Appendix Table A for full list of countries with Hofstede's Cultural Dimensions and Appendix Table B for data source.

Trust. To also capture the relation between standard trust and perception of favoritism, this study used the aggregated single-item mean score of standard trust from the World Values Survey across all six waves from 1981 to 2014 (Inglehart et al., 2018). The item asked, "Generally speaking, would you say that most people can be trusted or that you need to be very careful in dealing with people?" The item was a dichotomous scale with choices of 1 (Most people can be trusted) and 2 (Need to be very careful). The scores available for each country at each wave were averaged to obtain a continuous score. The scores are reverse coded so that higher values indicate higher trust for 
Table 1. Power Analyses for Regression and PLS-SEM Analyses for Hofstede and GLOBE Models

\begin{tabular}{|c|c|c|c|c|c|c|c|c|c|c|}
\hline \multirow[b]{2}{*}{$\begin{array}{c}\text { Outcome } \\
\text { Path }\end{array}$} & \multicolumn{5}{|c|}{ Hofstede } & \multicolumn{5}{|c|}{ GLOBE } \\
\hline & $\mathbf{N}$ & Vars & $\mathbf{R}^{2}$ & $\mathbf{f}^{2}$ & Power & $\mathbf{N}$ & Vars & $\mathbf{R}^{2}$ & $\mathbf{f}^{2}$ & Power \\
\hline Trust & 65 & 4 & 0.442 & 0.792 & 1.000 & 55 & 6 & 0.418 & 0.718 & 0.998 \\
\hline Favoritism & 65 & 5 & 0.678 & 2.106 & 1.000 & 55 & 7 & 0.690 & 2.226 & 1.000 \\
\hline $\begin{array}{l}\text { Nepotism/ } \\
\text { Cronyism }\end{array}$ & 65 & 5 & 0.715 & 2.509 & 1.000 & 55 & 7 & 0.702 & 2.356 & 1.000 \\
\hline
\end{tabular}

outgroup others. See Appendix Table A for full list of countries with this variable.

\section{Control Variable}

Prior studies have shown that perceptions of corruption were largely related to economic production (Davis \& Ruhe, 2003; Husted, 1999; Seleim \& Bontis, 2009). Further, economic development has been shown to account for changes in cultural dimensions (Beugelsdijk \& Welzel, 2018). To control for possible relations between economic development and favoritism, as well as any possible influences resulting from cultural change, the 2017 Gross Domestic Product per capita data for Purchasing Power Parity (GDP PPP) from The World Bank (2017) was used (except in the case of Taiwan, where the GDP PPP information was pulled from the International Monetary Fund, 2017).

\section{Analytical Plan}

A bi-variate correlation analysis was used to examine simple correlation relations between favoritism outcomes and cultural dimension predictors. Conceptually and statistically relevant variables were then analyzed in hierarchical regression models to assess the increase in variance explained following the inclusion of the Trust variable. Following the process outlined for mediation analysis by Baron and Kenny (1986), cultural dimensions and practices that significantly correlated with both the outcome variables and mediating Trust variable were then analyzed using partial least squares structural equation modeling (PLS-SEM) using SmartPLS 3.0 (Ringle, Wende, \& Becker, 2015). Relevant cultural dimensions and practices were used as items to construct a single latent variable to denote cultural values related to favoritism, following the methodology used in Rossberger and Krause (2015).
A PLS-SEM analysis allows us to examine the direct relation between culture and perception of favoritism as well as the mediating, indirect role of Trust. In comparison to the more common covariance-based SEM, PLS-SEM offers the advantage of running complex models using smaller sample sizes (Chin \& R. Newsted, 1999; Henseler et al., 2014; Reinartz, Haenlein, \& Henseler, 2009) with single or two indicator latent variables with no convergence issues (Hair, Hult, Ringle, \& Sarstedt, 2019). PLS-SEM is also recommended for testing predictive models and theory development (Henseler et al., 2014; Reinartz et al., 2009). Due to the small sample size and predictive, rather than confirmatory, purpose of this paper, we utilized PLS-SEM for our analyses.

Following recommendations to run power analyses (Hair et al., 2019; Hair, Ringle, \& Sarstedt, 2011; Marcoulides \& Chin, 2013), we utilized GPower 3.1 (Faul, Erdfelder, Buchner, \& Lang, 2009; Faul, Erdfelder, Lang, \& Buchner, 2007) to conduct a post-hoc multiple regression power analysis, suitable for PLS-SEM (Hair et al., 2019), at both the mediator and outcome paths (Table 1). Each path presented strong statistical power for detecting significant results. Additionally, robustness checks were conducted for nonlinear effects.

\section{Results}

Correlation results of Hofstede's Cultural Dimensions and perception of favoritism variables are given in Table 2. Power Distance, Collectivism, and Uncertainty Avoidance were positively correlated with both outcome variable, supporting Hypotheses 1, 3, and 4. However, Long-Term Orientation was not significantly related to either outcome variable, rejecting Hypothesis 5. Indulgence-restraint was negatively correlated with perceived nepotism/cronyism but not related to 


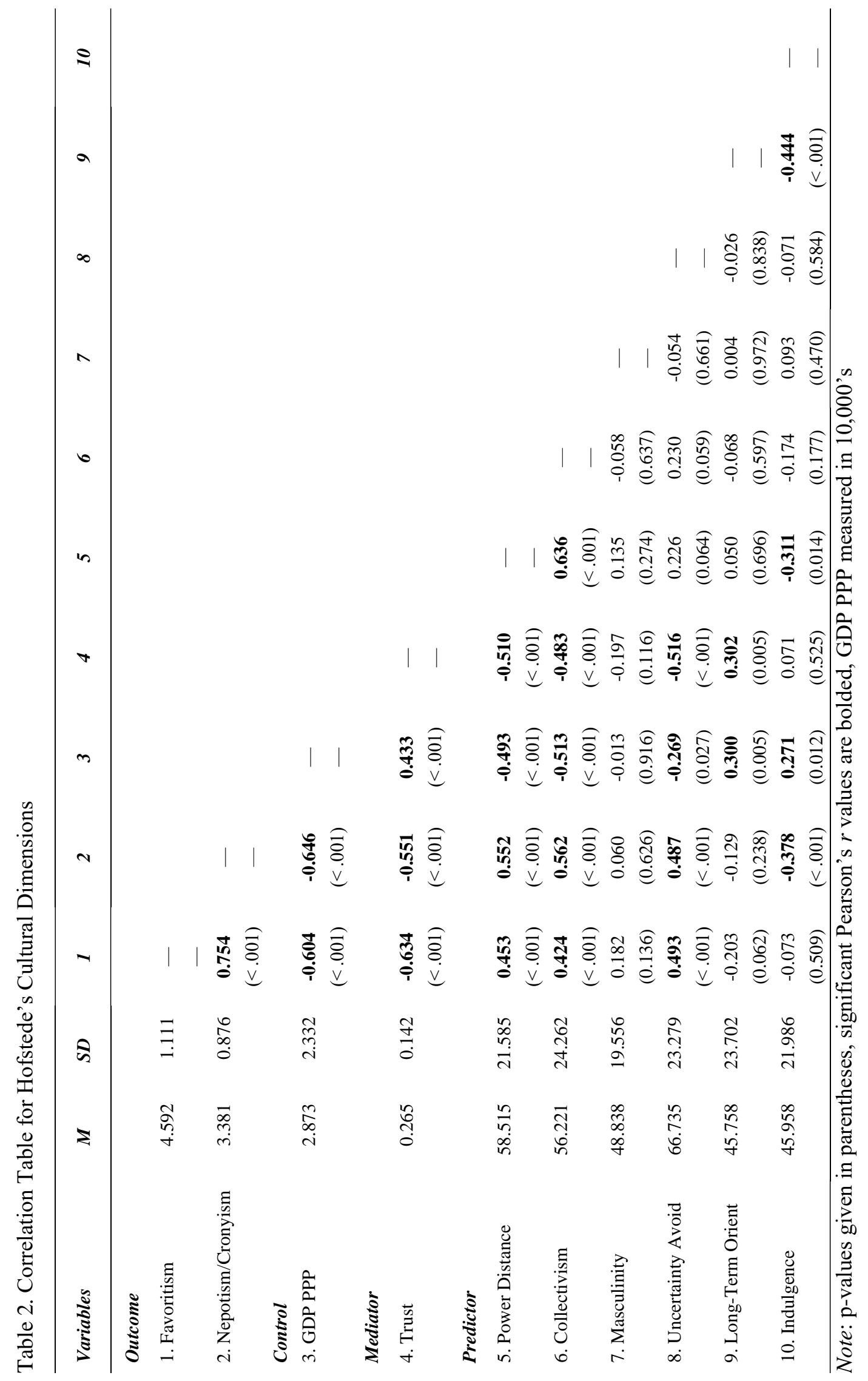



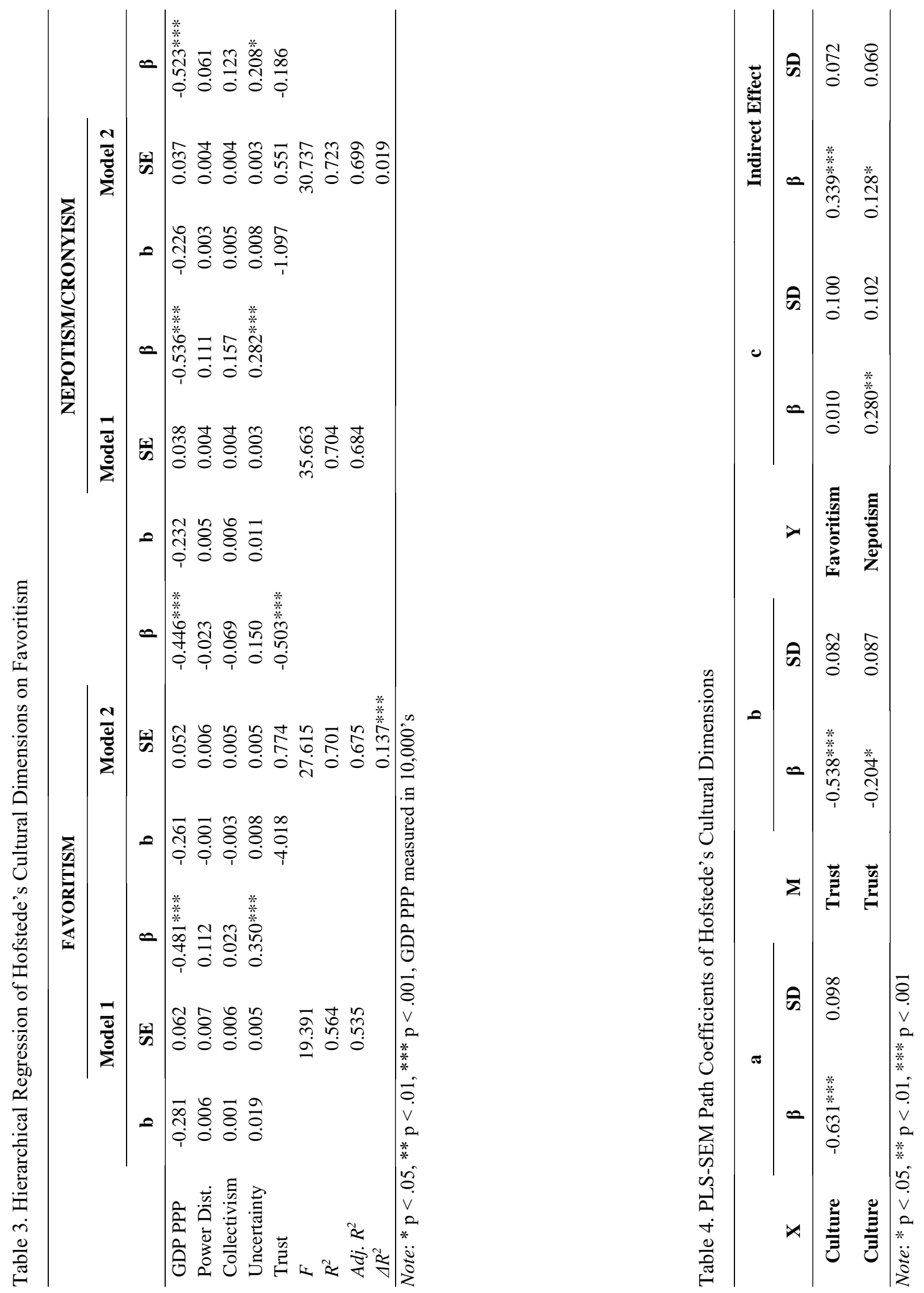
Figure 1. Mediation Model of Trust Mediating the Relation Between Culture and Favoritism and Nepotism/Cronyism

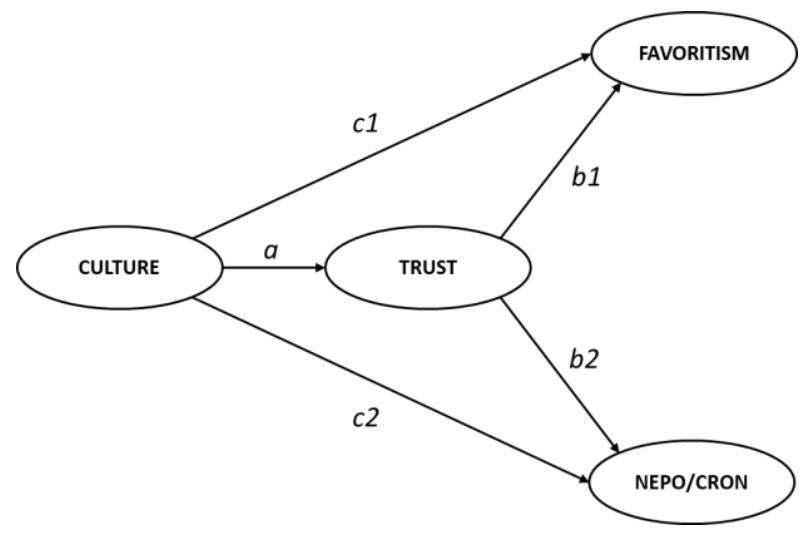

favoritism, partially supporting Hypothesis 7a, and Masculinity-Femininity was not significantly related to either outcome variables, supporting Hypothesis 7b. Outgroup trust was negatively related to both outcome variables, supporting Hypotheses 6a-b.

Hierarchical linear regression analyses for Favoritism and Nepotism/Cronyism are given in Table 3 with cultural dimensions that were significant bivariate correlates with both outcome variables. In the regression models with Favoritism as the outcome variable, Uncertainty Avoidance was a significant predictor, controlling for all other variables $(p<0.001)$. In Model 2 , the inclusion of Trust significantly improved R2 ( $<<0.001)$, and Trust was a significant predictor of Favoritism ( $\mathrm{p}<$ 0.001). Uncertainty Avoidance became marginally significant in Model $2(\mathrm{p}=0.080)$ suggesting an indirect mediation effect of Trust. In the regression models with Nepotism/Cronyism as the outcome variable, Uncertainty Avoidance likewise was a significant predictor $(\mathrm{p}<0.001)$ and remained significant $(p=0.013)$ with the inclusion of Trust in Model 2. Trust was marginally significant, controlling for all other variables $(\mathrm{p}=0.051)$.

To examine the mediation effects of Trust, a PLSSEM analysis was conducted with the structural model given in Figure 1. Path coefficients and indirect effect results are given in Table 4. The Culture latent variable was constructed using Power Distance, Collectivism, and Uncertainty Avoidance as items (loadings range from 0.638 $0.822), \omega=0.683$. In line with correlation and regression analyses, Culture was significantly related to Trust $(\mathrm{p}<0.001)$ and Trust was significantly related to both Favoritism $(\mathrm{p}<0.001)$ and Nepotism/Cronyism ( $\mathrm{p}=0.005)$. Culture was fully mediated by Trust in its relation to Favoritism ( $\mathrm{p}<0.001$ ) and partially mediated by Trust in its relation to Nepotism/Cronyism ( $\mathrm{p}=0.033)$, supporting Hypothesis $6 \mathrm{c}-\mathrm{d}$.

GLM mediation analysis was used to examine if equal weighted loadings of cultural item yielded the same results. GLM mediation results were almost identical to PLS-SEM analyses; Culture was negatively related to Trust $(\beta=-0.626, \mathrm{p}<0.001)$ and Trust was significantly related to both Favoritism $(\beta=-0.541, \mathrm{p}<0.001)$ and Nepotism/Cronyism $(\beta=-0.206, p=0.020)$. The indirect effect of Trust for Favoritism $(\beta=0.339, \mathrm{p}$ $<0.001)$ and Nepotism/Cronyism $(\beta=0.129, \mathrm{p}=$ 0.033 ) were significant. Robustness checks of nonlinear effects using Ramsey's RESET method (Ramsey, 1969) yielded non-significant results for nonlinearity of predictor variables at end paths of Trust $(\mathrm{F}(8,52)=1.714, \mathrm{p}=0.117)$, Favoritism $(\mathrm{F}(10,49)=1.019, \mathrm{p}=0.442), \quad$ and Nepotism/Cronyism $(F(10,49)=1.800, \mathrm{p}=0.086)$, reflecting the robustness of linear effects models used in this study.

\section{Discussion}

Bivariate correlation results went in the expected direction in which Power Distance, Collectivism, and Uncertainty Avoidance were positively related to greater perception of Favoritism and Nepotism/Cronyism. However, hierarchical linear regression results suggest that after controlling for all other variables, the country-level extent of trust in others played a greater role than culture for Favoritism. However, this trend was not observed in Nepotism/Cronyism, suggesting that when the favoritism dynamic is not aimed at friends or family but rather other targets (in this case, firms), the direct motivator for engaging in favoritism may not stem from cultural values and ideals but one's general distrust of others' intentions or motives. PLS-SEM mediation results support this notion; all three relevant cultural dimensions were highly negatively correlated with Trust, which in turn was negatively correlated with Favoritism and Nepotism/Cronyism. Thus, cultures high in Power Distance, Collectivism, and Uncertainty Avoidance typically exhibit less trust of others which may 
result in greater prevalence of Favoritism and Nepotism/Cronyism.

\section{Study 2: The Relation Between GLOBE's Cultural Orientations and Favoritism}

While Power Distance, Collectivism, and Uncertainty Avoidance were used as indicators of the latent variable of culture related to favoritism in Study 1 , the three items did not produce a desirable reliability statistic. To examine the conceptual and statistical robustness of the results in Study 1, the same methods were used with the GLOBE cultural orientations data in Study 2 with societal practices that were developed from reconceptualization of Hofstede's Cultural Dimensions. Following Study 1, the same outcome, control, and mediator variables were used in Study 2.

\section{Measures}

GLOBE's Cultural Orientation Practices. All cultural practices of the nine orientations of 1) (Weak) Uncertainty Avoidance, 2) Future Orientation, 3) Power Distance, 4) Institutional Collectivism, 5) Humane Orientation, 6) Performance Orientation, 7) Familism, 8) Gender Egalitarianism, and 9) Assertiveness are included in this study. Cultural practices were measured with questions inquiring participants' perceptions of society "as is". Each orientation was measured with 4-5 items (for detailed methodology and items, see House et al., 2004). Of the original 62 cultures measured in GLOBE, 57 countries had overlapping data with the outcome variables and were included in this study. See Appendix Table A for full list of countries with GLOBE's Cultural Orientations and Appendix Table B for data source.

\section{Results}

Correlation results of GLOBE's Cultural Practices and perception of favoritism variables are given in Table 5. Weak Uncertainty Avoidance, Future Orientation, and Institutional Collectivism were negatively correlated with both outcome variables, supporting Hypotheses 2, 3, and 5. Power Distance and Familism were positively correlated with both outcome variables, partially supporting Hypotheses 1 and 4. Assertiveness was weakly, but positively, correlated with only perceived general favoritism, partially supporting Hypothesis 7e. Humane Orientation and Gender Egalitarianism were not related to either outcome variables, supporting Hypotheses 7c-d.
Hierarchical regression analysis results are given in Table 6. As in Study 1, cultural variables that were significant bivariate correlates of favoritism were included in the regression models. In the regression models with favoritism as the outcome, only Institutional Collectivism was a significant predictor, controlling for all other variables $(\mathrm{p}=$ 0.025). However, in Model 2, the inclusion of the Trust variable significantly improved the $\mathrm{R} 2(\mathrm{p}<$ 0.001 ) and resulted in Institutional Collectivism becoming non-significant ( $p=0.365$ ). Thus, the significant correlation between Trust and Institutional Collectivism and the shift from significance to non-significance following the inclusion of Trust in the model suggests a possible mediation effect. In the regression models with Nepotism/Cronyism as the outcome, Future Orientation and Familism were significant predictors, controlling for all other variables (pfut $=0.045$; pfam < 0.001). The inclusion of Trust in the second model did not result in a significant improvement of R2 ( $p=0.198)$.

To examine the mediation effects of Trust, the same structural model (Figure 1) as Study 1 was constructed in Study 2 with GLOBE's Cultural Orientations. The five cultural orientations that were significantly correlated with both outcome variables (i.e., Weak Uncertainty Avoidance, Power Distance, Future Orientation, Institutional Collectivism, and Familism) were used as items for the latent variable of Culture (related to favoritism), $\omega=0.828$. PLS-SEM results are given in Table 7. In line with the regression results (Table 6), Trust fully mediated the relation between Culture and Favoritism ( $\mathrm{p}=0.006)$ while no such mediation was found for Nepotism ( $p=0.163$ ), supporting Hypothesis $6 \mathrm{c}$ but not $6 \mathrm{~d}$.

GLM mediation analyses were also run to examine if equal weighting of the Culture latent variable yielded same results in which Culture was fully mediated by Trust in its relation to Favoritism ( $\mathrm{p}=$ 0.001 ) but not with Nepotism ( $p=0.191)$. Culture, instead, had a significant direct effect with Nepotism ( $p<0.001$ ). Robustness checks of nonlinear effects using Ramsey's RESET method (Ramsey, 1969) yielded non-significant results for nonlinearity of predictor variables at end paths of Trust $(\mathrm{F}(12,36)=0.989, \mathrm{p}=0.478)$, Favoritism $(\mathrm{F}(14,33)=0.822, \quad \mathrm{p}=0.642), \quad$ and Nepotism/Cronyism $(F(14,33)=0.825, \mathrm{p}=0.639)$, 


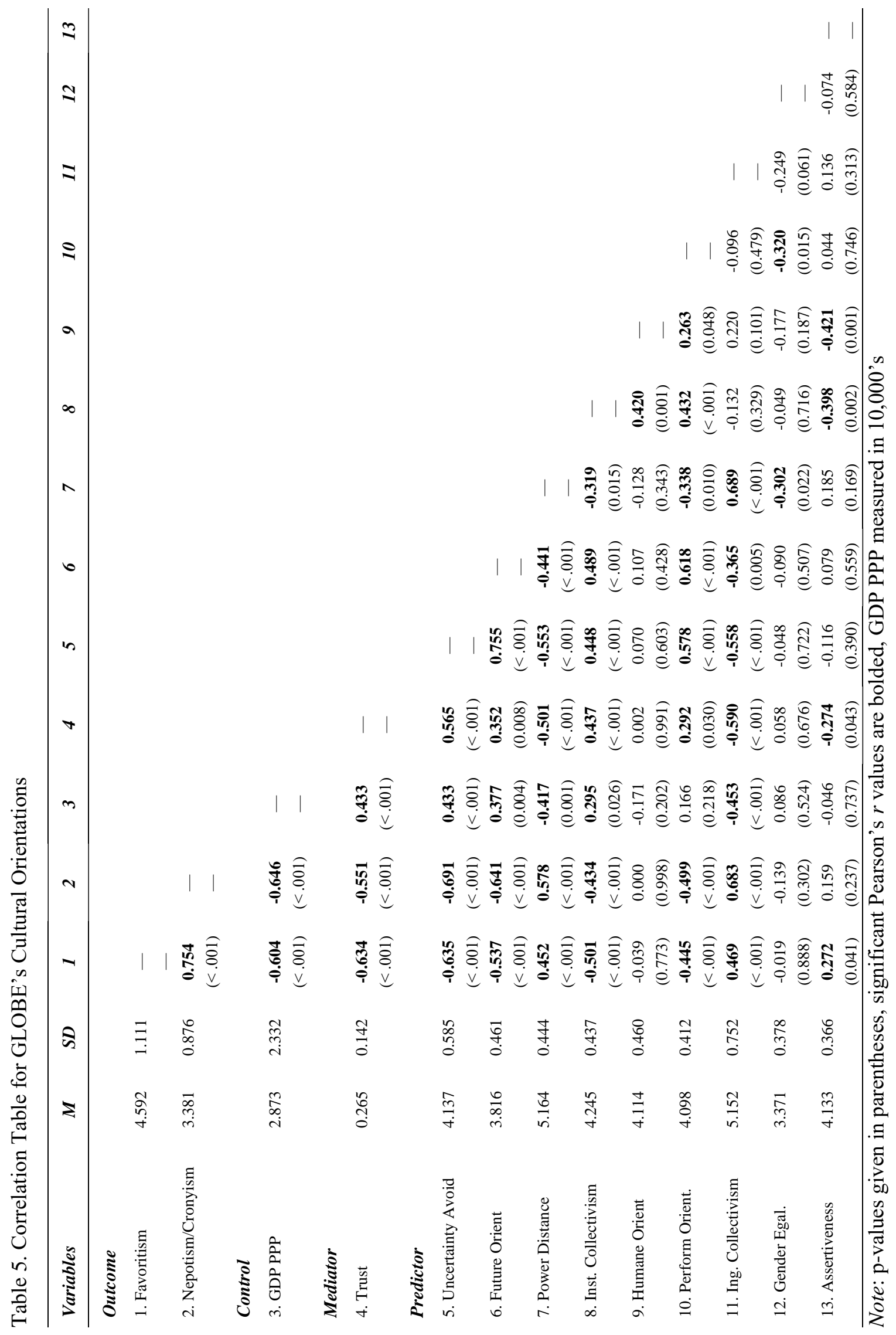



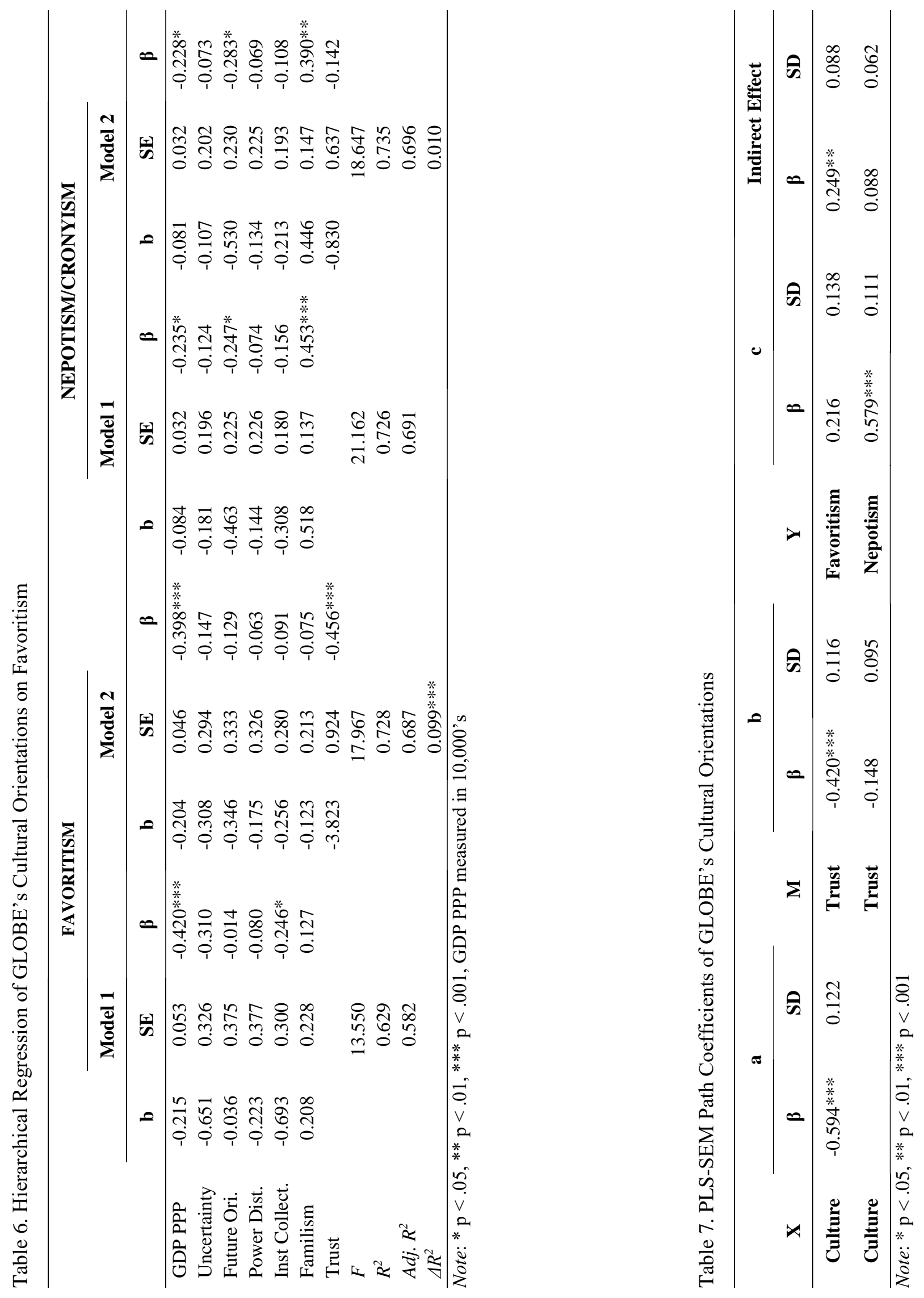
reflecting the robustness of linear effects models used in this study.

To ensure that the discrepancy in mediation results from Study 1 and Study 2 (i.e., the significant and non-significant indirect effects of Trust on Culture and Nepotism/Cronyism, respectively) was not due to the different composition of countries analyzed or items used to construct the Culture latent variable, both Study 1 and Study 2 mediation models were reanalyzed with only the overlapping countries between Hofstede and GLOBE's cultures ( $\mathrm{n}=46)$ and Institutional Collectivism and Future Orientation items removed from the latent Culture variable for the GLOBE model. However, the results remained same with the indirect effect being significant for the Hofstede model $(\mathrm{p}=0.031)$ and nonsignificant for the GLOBE model $(\mathrm{p}=0.145)$. To ensure that unequal weighting of the items for the latent Culture variable was not causing the discrepancy in significance, GLM mediation analyses were conducted. However, results revealed the same patterns, suggesting that suggesting that the discrepancy is most likely a byproduct of how the variables were conceptually constructed.

\section{Discussion}

Results of Study 2 partially support the findings of Study 1 . While the direction and general patterns mirror that of Study 1, a notable discrepancy was found for the mediating effect of Trust between the relation of Culture and Nepotism/Cronyism. Subsequent analyses indicate that the discrepancy may be a byproduct of low inter-item reliability of Hofstede's Cultural Dimensions. This may be reflective of the differences in which Hofstede's Cultural Dimensions and GLOBE's Cultural Orientations were constructed, i.e., the prior being more exploratory of latent cultural values and the latter being more conceptually driven based on researchers' prior knowledge of cultural mechanisms. Nonetheless, findings from Study 2 supported the findings of Study 1 regarding the full mediation effect of Trust on the relation between Culture and Favoritism as well as the direct effect of Culture on Nepotism/Cronyism.

\section{General Discussion}

Overall, results from this study generally support previous findings that have been conducted at the micro-level and provide insight into how those findings may have been reflective of a wider scale cultural phenomenon. With correlational analyses, we find that Collectivism (inclusive of Familism and Institutional Collectivism), Uncertainty Avoidance, and Power Distance are significantly related to both perceived general favoritism and nepotism/cronyism across both Hofstede's National Cultural Dimensions and GLOBE's Cultural Orientations. These results support prior propositions regarding cultural values of paternalism and particularism as antecedents of forms of favoritism (Khatri, 2009; Khatri \& Tsang, 2003), individual-level examinations of uncertainty avoidance and collectivism (Jeanquart-Barone \& Peluchette, 1999; Martinsons \& Davison, 2007), and cross-national studies of culture and perceived corruption (Davis \& Ruhe, 2003; Husted, 1999; Seleim \& Bontis, 2009; Yeganeh, 2014). Regression analyses suggest that among these cultural dimensions, Uncertainty Avoidance and Trust are key correlates of favoritism while Familism and Future Orientation are key correlates of nepotism/cronyism. Accordingly, Culture is mediated by Trust in its relation to favoritism, but not nepotism/cronyism.

Results for Hofstede's Masculinity-Femininity dimension and related GLOBE orientations generally showed no significant correlation to either outcome variables, supporting the conceptual rationale for its little relation to favoritism. Indulgence, on the other hand, was unexpectedly related to perceptions of nepotism/cronyism. At the conceptual level, it is difficult to assess why the results came about this way; at surface value, there is very little substance that is interpretable about the dimension that would suggest general favoritism and nepotism/cronyism would be regarded differently in indulgent or restraint cultures. Because the indulgence dimension, to an extent, also reflects a culture's looseness, the degree to which deviation from social norm is accepted, and valuation of family, those two values may be manifested in the correlation for nepotism/cronyism but not general favoritism. Still, future examination and studies should aim to decompose the dimension into various subparts to explore possible patterns.

Another surprising finding was the striking difference found between Hofstede's Long-Term Orientation and GLOBE's Future Orientation. While future orientation is strongly, negatively 
correlated with both outcome variables, long-term orientation is not correlated with either outcome variables. This difference may stem from the way the two dimensions were measured; long-term orientation is a measure of thrift, national pride, and service to others. Only thrift is a clear measure of future planning whereas service to others may be more similar to GLOBE's Humane Orientation. Thus, on a conceptual level, long-term orientation may be a composite of other values in addition to future orientation. In this regard, it would make sense that while future orientation is negatively related to favoritism, long-term orientation fails to show the same significant results.

Overall, this study adds to the current body of literature that examines cross-national cultural values and its relations to unethical conduct like corruption (Davis \& Ruhe, 2003; Husted, 1999; Seleim \& Bontis, 2009; Yeganeh, 2014) and bribery (Wated \& Sanchez, 2005; Zheng, Ghoul, Guedhami, \& Kwok, 2013). We observe that cultures high in familism, collectivism, power distance, and uncertainty avoidance tend to exhibit greater distrust of others. This, in turn, was related to greater favoritism regarding political interactions with firms. Because such interactions can be construed as transactions, engagement in favoritism may be deemed a rational decision to safeguard oneself from risks associated with unknown parties. In other words, by engaging with known parties, one's beliefs about future reciprocal gains are less unknown and more predictable. In this regard, this study supports the notion that uncertain situations or outcomes will necessitate interactions with trusted, close individuals, thereby promoting the establishment of commitment relationships (Kollock, 1994; Yamagishi, Cook, et al., 1998; Yamagishi et al., 1996, 1995). On the other hand, we do not observe a robust indirect effect of trust regarding nepotism/cronyism. Thus, it may be such that one's distrust of others does not compel one to engage in nepotistic behavior, but rather that one engages in nepotistic behavior because it is the culturally normative decision. In other words, because friendships or kinships are often social commitment relationships, the cultural doctrine that govern the social dynamics of said relationships may induce preferences of ingroup love, rather than the transactional rationalization associated with beliefs of reciprocal behavior from the opposing party. Overall, the discrepancy found between favoritism and nepotism/cronyism alludes to differences in which depending on the beneficiary or situation, cultural values may be related to the use of beliefs (related to reciprocal behavior) and preferences (related to attention to ingroup wellbeing).

It is worth noting, however, that higher level of favoritism does not necessarily foreshadow negative outcomes. Further, because the outcome variables utilize items that inquire about the perceptions of favoritism, it does not measure the degree to which the surveyed individuals perceive such actions to be problematic. Rather, this study merely assesses whether such actions may be more routinely perceived in cultures that emphasize certain cultural values. In that regard, the findings of this study indicate that people in cultures that are high in collectivism, familism, power distance, and strong uncertainty avoidance tend to perceive more favoritism in their working environments. On the other hand, people in cultures high in trust, institutional collectivism, and future orientation perceive less. Future studies may attempt to capture the degree to which surveyed respondents perceive favoritism to be negative (i.e., impedes development) or unethical (i.e., reflects unfairness) to gain a more nuanced understanding how societal values of ethics or morals play a role in the appraisal of favoritism.

\section{Implications}

This study's results provide numerous conceptual and practical implications for firms and businesses interested in disentangling favoritism within the workplace or during interactions with public officials. Because societal culture can permeate down into organizational culture, firms and businesses situated in countries marked by high collectivism, familism, power distance, and uncertainty avoidance may need to pay special attention to how social commitment relationships or transactions are being conducted. Countries that are also mired with social angst or distrust of others, say from, inadequate protection of parties and transactions, can be particularly attentive to favoritism in interactions between public officials and firms. Within such environments, firms and businesses may benefit from having established formal contracts, as opposed to reliance on informal, social contracts, to guide business decisions. 
Stronger and more frequent third-party auditing of ethical interactions between firms and officials in these cultures may allow for more accurate recording of the prevalence of favoritism. If the goal is to reduce favoritism within the workplace, endorsement of cultural values that are negative correlates of favoritism, such as maintenance of group goals and future planning, may prove fruitful. On the other hand, attempts at aiming at empathyladen constructs related to Masculinity-Femininity may not be beneficial in curbing favoritism within the workplace.

\section{Limitations}

There are several limitations to this study that should be considered. First, cultural dimensions inherently oversimplify and generalize the nature of a culture's values and norms. While this study's intention was to provide a broad, conceptual model with which one may extrapolate the relation between culture and favoritism, future studies can provide nuance to this model by examining the within-country and within-organization variations to favoritism. Secondly, this study primarily relies on country data using self-reported measures of cultural orientation and perception of favoritism as the predictor and outcome variables, respectively. The subjective nature of perceptions of favoritism is particularly worth noting because cultures may largely vary in the degree to which such behaviors are construed as actually being unethical. However, because objective measures of corruption are rarely both available and reliable, the reports of individual perceptions of favoritism offer an alternative to assessing the extent to which those affected perceive it to be problematic.

The sample composition is another limitation that should be considered; due to the small sample size of countries with available cultural variable data, methods of conceptual confirmatory analyses, such as covariance-based structural equation modeling, are not possible. Additionally, this study was limited in using the general trust variable from the World Values Survey as a proxy for one's dispositional trust towards others. Due to the small number of countries with overlapping data with cultural variables, more specific composite variables of trust towards ingroup members were not available to use in this study. Future research may incorporate favoritism measures in conjunction with cultural orientation measures at the individual level to examine more complicated relations between variables. It is also worth noting that out of the total 97 unique countries/cultures used in this study, all members of the Organisation for Economic Co-operation and Development (OECD) (for a full list, see Appendix Table A) are included. OECD countries typically have highincome economies, exhibit high human development, and the doctrine of the organization may also facilitate similar democratic efforts or policies that may not otherwise reflect the developmental climate of non-member countries.

Favoritism and nepotism/cronyism were also asked in different parts in the World Competitiveness Report. These variables may then reflect the degree of favoritism in two different sectors; government and business. The nepotism/cronyism variable inquired about both family and friends and it is not certain whether one would observe significant differences should the distinction between family and friends had been clearer (i.e., nepotism vs. cronyism). Future studies may address both these issues by comparing the nature of favoritism across different sectors and separating favoritism into different components. Lastly, the variables used in this study stemmed from different timepoints (i.e., Hofstede's Cultural Dimensions from 1967-1973, GLOBE's Cultural Orientations from 1994-1997, WVS's Trust from 1981-2014, and Favoritism measures from 2016-2017). As discussed in previous sections, cross-cultural differences tend to be robust to generational effects, even when culture itself changes (Beugelsdijk \& Welzel, 2018; Hofstede et al., 2010). Nonetheless, while evidence from Beugelsdijk and Welzel (2018) suggests that generational effects thus far have not threatened cross-cultural differences, it is not certain that future changes will be as robust as it has been in the past century. Thus, future studies should aim to replicate the findings of this study with newer measures of cultural dimensions and orientations, where possible, to examine the effects of changes to culture or cross-cultural differences, if any, to examine the robustness of culture's affinity to favoritism.

\section{Conclusion}

Tackling favoritism in the workplace and between firms is a challenging endeavor that entails a myriad of cultural considerations. Because the incentive to engage in favoritism behavior is not 
derived from just self-interest, the concept is muddied by the complexities of understanding the psychology of interpersonal and intergroup interactions. Nonetheless, this study provides an addition to the current body of literature examining culture and favoritism. In short, the cultural values endorsed at the individual-level manifest into observable trends at the cross-national level. This study primarily serves as an exploratory investigation seeking to establish a foundation for future studies to probe into the intricate cultural mechanisms underlying favoritism. Future studies may benefit by also inquiring into the organizational and government outcomes associated with having high levels of favoritism.

\section{References}

Abramson, J. (2018, March 6). Nepotism and corruption: The handmaidens of Trump's presidency | Jill Abramson. The Guardian. Retrieved from

https://www.theguardian.com/commentisfree/2018/mar/06/ nepotism-corruption-handmaiden-trump-presidency

Akbar, Y. H., \& Vujić, V. (2014). Explaining corruption: The role of national culture and its implications for international management. Cross Cultural Management: An International Journal, 21(2), 191-218. https://doi.org/10.1108/CCM-032013-0050

Allik, J., \& Realo, A. (2004). Individualism-Collectivism and Social Capital. Journal of Cross-Cultural Psychology, 35(1), 29-49. https://doi.org/10.1177/0022022103260381

Banfield, E. C. (1958). Moral Basis of a Backward Society (Underlining edition). New York: Free Press.

Barnett, K., \& McCormick, J. (2004). Leadership and Individual Principal-Teacher Relationships in Schools. Educational Administration Quarterly, 40(3), 406-434.

https://doi.org/10.1177/0013161X03261742

Baron, R. M., \& Kenny, D. A. (1986). The moderator-mediator variable distinction in social psychological research:

Conceptual, strategic, and statistical considerations. Journal of Personality and Social Psychology, 51(6), 1173-1182.

BBC News. (2018, January 30). Argentine president bans nepotism. BBC World News. Retrieved from https://www.bbc.com/news/world-latin-america-42868439

Beugelsdijk, S., \& Welzel, C. (2018). Dimensions and Dynamics of National Culture: Synthesizing Hofstede With Inglehart. Journal of Cross-Cultural Psychology, 49(10), 1469-1505. https://doi.org/10.1177/0022022118798505

Blodgett, J. G., Bakir, A., \& Rose, G. M. (2008). A test of the validity of Hofstede's cultural framework. Journal of Consumer Marketing, 25(6), 339-349.

https://doi.org/10.1108/07363760810902477
Boutilier, R. (2009). Globalization and the Careers of Mexican Knowledge Workers: An Exploratory Study of Employer and Worker Adaptations. Journal of Business Ethics, 88(2), 319333. https://doi.org/10.1007/s10551-009-0284-9

Casey-Campbell, M., \& Martens, M. L. (2009). Sticking it all together: A critical assessment of the group cohesionperformance literature. International Journal of Management Reviews, 11(2), 223-246. https://doi.org/10.1111/j.14682370.2008.00239.x

Chen, Y.-R., Brockner, J., \& Chen, X.-P. (2002). Individualcollective primacy and ingroup favoritism: Enhancement and protection effects. Journal of Experimental Social Psychology, 38(5), 482-491. https://doi.org/10.1016/S00221031(02)00018-5

Chen, Y.-R., Brockner, J., \& Katz, T. (1998). Toward an explanation of cultural differences in in-group favoritism: The role of individual versus collective primacy. Journal of Personality and Social Psychology, 75, 1490-1502. https://doi.org/10.1037//0022-3514.75.6.1490

Chin, W., \& R. Newsted, P. (1999). Structural Equation Modeling Analysis with Small Samples Using Partial Least Square. In Statistical Strategies for Small Sample Research (pp. 307-341). Thousand Oaks, CA: SAGE Publications.

Davis, J. H., \& Ruhe, J. A. (2003). Perceptions of Country Corruption: Antecedents and Outcomes. Journal of Business Ethics, 43(4), 275-288.

https://doi.org/10.1023/A:1023038901080

Dickson, M., Nieminen, L., \& Biermeier-Hanson, B. (2012). Nepotism and organizational homogeneity: How the attraction-Selection-Attrition (ASA) process is accelerated by Nonmerit-Based decision making. In Nepotism in Organizations (pp. 93-128). Routledge/Taylor \& Francis Group.

Erickson, A. (2017). Analysis | The real danger of having Jared Kushner and Ivanka in the Trump administration. Retrieved February 2, 2019, from Washington Post website:

https://www.washingtonpost.com/news/worldviews/wp/2017 /07/26/trump-loves-nepotism-that-can-be-bad-fordemocracy/

Evans, C. R., \& Dion, K. L. (1991). Group Cohesion and Performance: A Meta-Analysis. Small Group Research, 22(2), 175-186. https://doi.org/10.1177/1046496491222002

Everett, J. A. C., Faber, N. S., \& Crockett, M. (2015). Preferences and beliefs in ingroup favoritism. Frontiers in Behavioral Neuroscience, 9. https://doi.org/10.3389/fnbeh.2015.00015

Faul, F., Erdfelder, E., Buchner, A., \& Lang, A.-G. (2009). Statistical power analyses using $G^{*}$ Power 3.1: Tests for correlation and regression analyses. Behavior Research Methods, 41(4), 1149-1160.

https://doi.org/10.3758/BRM.41.4.1149

Faul, F., Erdfelder, E., Lang, A.-G., \& Buchner, A. (2007). G*Power 3: A flexible statistical power analysis program for the social, behavioral, and biomedical sciences. Behavior Research Methods, 39(2), 175-191.

https://doi.org/10.3758/BF03193146 
Gully, S. M., Devine, D. J., \& Whitney, D. J. (1995). A MetaAnalysis of Cohesion and Performance: Effects of Level of Analysis and Task Interdependence. Small Group Research, 26(4), 497-520. https://doi.org/10.1177/1046496495264003

Hair, J. F., Hult, G. T. M., Ringle, C., \& Sarstedt, M. (2019). A Primer on Partial Least Squares Structural Equation Modeling (PLS-SEM) (2nd ed.). SAGE Publications.

Hair, J. F., Ringle, C. M., \& Sarstedt, M. (2011). PLS-SEM: Indeed a Silver Bullet. Journal of Marketing Theory and Practice, 19(2), 139-152. https://doi.org/10.2753/MTP10696679190202

Henseler, J., Dijkstra, T. K., Sarstedt, M., Ringle, C. M., Diamantopoulos, A., Straub, D. W., ... Calantone, R. J. (2014). Common Beliefs and Reality About PLS: Comments on Rönkkö and Evermann (2013). Organizational Research Methods, 17(2), 182-209. https://doi.org/10.1177/1094428114526928

Hershfield, H. E., Cohen, T. R., \& Thompson, L. (2012). Short horizons and tempting situations: Lack of continuity to our future selves leads to unethical decision making and behavior. Organizational Behavior and Human Decision Processes, 117(2), 298-310.

https://doi.org/10.1016/j.obhdp.2011.11.002

Hofstede, G. (2010). The GLOBE debate: Back to relevance. Journal of International Business Studies, 41(8), 1339-1346. https://doi.org/10.1057/jibs.2010.31

Hofstede, G. (2011). Dimensionalizing Cultures: The Hofstede Model in Context. Online Readings in Psychology and Culture, 2(1). https://doi.org/10.9707/2307-0919.1014

Hofstede, G., Hofstede, G. J., \& Minkov, M. (2010). Cultures and Organizations: Software of the Mind, Third Edition (3 edition). New York: McGraw-Hill Education.

Holden, E. (2018, December 20). Trump conservation pick triggers question of "favoritism or connections." The Guardian. Retrieved from https://www.theguardian.com/usnews/2018/dec/19/aurelia-skipwith-fish-wildlife-agencydonald-trump

House, R. J., Hanges, P. J., Javidan, M., Dorfman, P. W., \& Gupta, V. (2004). Culture, Leadership, and Organizations: The GLOBE Study of 62 Societies. SAGE Publications.

Huff, L., \& Kelley, L. (2003). Levels of Organizational Trust in Individualist Versus Collectivist Societies: A Seven-Nation Study. Organization Science, 14(1), 81-90. https://doi.org/10.1287/orsc.14.1.81.12807

Husted, B. W. (1999). Wealth, Culture, and Corruption. Journal of International Business Studies, 30(2), 339-359. https://doi.org/10.1057/palgrave.jibs.8490073

Inglehart, R., Haerpfer, C., Moreno, A., Welzel, C., Kizilova, K., Diez-Medrano, J., ... Puranen, B. (2018). World Values Survey: All Rounds-Country-Pooled Datafile. Retrieved from http://www.worldvaluessurvey.org/WVSDocumentationWVL.j sp

Jeanquart-Barone, S., \& Peluchette, J. V. (1999). Examining the impact of the cultural dimension of uncertainty avoidance on staffing decisions: A look at US and German firms. Cross
Cultural Management: An International Journal, 6(3), 3-12. https://doi.org/10.1108/13527609910796960

Kennedy, J. A., \& Anderson, C. (2017). Hierarchical rank and principled dissent: How holding higher rank suppresses objection to unethical practices. Organizational Behavior and Human Decision Processes, 139, 30-49. https://doi.org/10.1016/j.obhdp.2017.01.002

Khatri, N. (2009). Consequences of Power Distance Orientation in Organisations. Vision, 13(1), 1-9.

https://doi.org/10.1177/097226290901300101

Khatri, N., \& Tsang, E. W. K. (2003). Antecedents and Consequences of Cronyism in Organizations. Journal of Business Ethics, 43(4), 289-303. https://doi.org/10.1023/A:1023081629529

Kollock, P. (1994). The Emergence of Exchange Structures: An Experimental Study of Uncertainty, Commitment, and Trust. American Journal of Sociology, 100(2), 313-345. https://doi.org/10.1086/230539

Lapalombara, J. (1994). Structural and Institutional Aspects of Corruption. Social Research, 61(2), 325-350.

Ledeneva, A. V. (1998). Russia's Economy of Favours: Blat, Networking and Informal Exchange. Cambridge University Press.

Ledeneva, A. V. (2009). From Russia with Blat: Can Informal Networks Help Modernize Russia? Social Research: An International Quarterly, 76(1), 257-288.

Marcoulides, G. A., \& Chin, W. W. (2013). You Write, but Others Read: Common Methodological Misunderstandings in PLS and Related Methods. In H. Abdi, W. W. Chin, V. Esposito Vinzi, G. Russolillo, \& L. Trinchera (Eds.), New Perspectives in Partial Least Squares and Related Methods (pp. 31-64). Springer New York.

Markus, H., \& Kitayama, S. (1991). Culture and the Self: Implications for Cognition, Emotion, and Motivation. Psychological Review, 98, 224-253.

https://doi.org/10.1037/0033-295X.98.2.224

Martinsons, M. G., \& Davison, R. M. (2007). Strategic decision making and support systems: Comparing American, Japanese and Chinese management. Decision Support Systems, 43(1), 284-300. https://doi.org/10.1016/j.dss.2006.10.005

Medoff, M. H. (2003). Editorial Favoritism in Economics? Southern Economic Journal, 70(2), 425-434. https://doi.org/10.2307/3648979

Park, T. H. (2004). The Influences of Familism on Interpersonal Trust of Korean Public Officials. International Review of Public Administration, 9(1), 121-135. https://doi.org/10.1080/12294659.2004.10805044

Ramsey, J. B. (1969). Tests for Specification Errors in Classical Linear Least-Squares Regression Analysis. Journal of the Royal Statistical Society: Series B (Methodological), 31(2), 350-371. https://doi.org/10.1111/j.2517-6161.1969.tb00796.x

Realo, A., Allik, J., \& Greenfield, B. (2008). Radius of Trust: Social Capital in Relation to Familism and Institutional 
Collectivism. Journal of Cross-Cultural Psychology, 39(4), 447-462. https://doi.org/10.1177/0022022108318096

Reinartz, W., Haenlein, M., \& Henseler, J. (2009). An empirical comparison of the efficacy of covariance-based and variancebased SEM. International Journal of Research in Marketing, 26(4), 332-344.

https://doi.org/10.1016/j.jiresmar.2009.08.001

Ringle, C. M., Wende, S., \& Becker, J.-M. (2015). SmartPLS 3 (Version 3). Retrieved from https://www.smartpls.com

Rossberger, R. J., \& Krause, D. E. (2015). Participative and Team-Oriented Leadership Styles, Countries' Education Level, and National Innovation: The Mediating Role of Economic Factors and National Cultural Practices. Cross-Cultural Research, 49(1), 20-56. https://doi.org/10.1177/1069397114534825

Seleim, A., \& Bontis, N. (2009). The relationship between culture and corruption: A cross-national study. Journal of Intellectual Capital, 10(1), 165-184.

https://doi.org/10.1108/14691930910922978

Sidani, Y. M., \& Thornberry, J. (2013). Nepotism in the Arab World: An Institutional Theory Perspective. Business Ethics Quarterly, 23(1), 69-96.

https://doi.org/10.5840/beq20132313

Tajfel, H., \& Turner, J. (1979). An Integrative Theory of Intergroup Conflict. In Organizational Identity: A Reader (pp. 56-65).

The World Bank. (2017). GDP per capita, PPP (current international \$) | Data. Retrieved August 30, 2018, from https://data.worldbank.org/indicator/NY.GDP.PCAP.PP.CD

Triandis, H. C. (1989). The Self and Social Behavior in Differing Cultural Contexts. Psychological Review, 96, 506. https://doi.org/10.1037//0033-295X.96.3.506

Triandis, H. C. (2001). Individualism-Collectivism and Personality. Journal of Personality, 69(6), 907-924. https://doi.org/10.1111/1467-6494.696169

Vriend, T., Jordan, J., \& Janssen, O. (2016). Reaching the top and avoiding the bottom: How ranking motivates unethical intentions and behavior. Organizational Behavior and Human Decision Processes, 137, 142-155.

https://doi.org/10.1016/j.obhdp.2016.09.003

Wang, C., Wu, B., Liu, Y., Wu, X., \& Han, S. (2015). Challenging emotional prejudice by changing self-concept: Priming independent self-construal reduces racial in-group bias in neural responses to other's pain. Social Cognitive and
Affective Neuroscience, 10(9), 1195-1201.

https://doi.org/10.1093/scan/nsv005

Wated, G., \& Sanchez, J. I. (2005). The Effects of Attitudes, Subjective Norms, Attributions, and Individualism-

Collectivism on Managers' Responses to Bribery in

Organizations: Evidence from a Developing Nation. Journal of Business Ethics, 61(2), 111-127.

https://doi.org/10.1007/s10551-005-8712-y

Wated, G., \& Sanchez, J. I. (2012). The cultural boundary of managing nepotism. In Nepotism in Organizations (pp. 199218). Routledge/Taylor \& Francis Group.

Wated, G., \& Sanchez, J. I. (2015). Managerial Tolerance of Nepotism: The Effects of Individualism-Collectivism in a Latin American Context. Journal of Business Ethics, 130(1), 45-57. https://doi.org/10.1007/s10551-014-2195-7

Yamagishi, T., Cook, K. S., \& Watabe, M. (1998). Uncertainty, Trust, and Commitment Formation in the United States and Japan. American Journal of Sociology, 104(1), 165-194. https://doi.org/10.1086/210005

Yamagishi, T., Jin, N., \& Miller, A. S. (1998). In-group Bias and Culture of Collectivism. Asian Journal of Social Psychology, 1(3), 315-328. https://doi.org/10.1111/1467-839X.00020

Yamagishi, T., Watabe, M., Hayashi, N., Takahashi, N., \& Yamagishi, M. (1996). Trust and commitment under social uncertainty. Research in Social Psychology, 11(3), 206-216. https://doi.org/10.14966/jssp.KJ00003724698

Yamagishi, T., Yamagishi, M., Takahashi, N., Hayashi, N., \& Watabe, M. (1995). Trust and Commitment Formation. The Japanese Journal of Experimental Social Psychology, 35(1), 23-34. https://doi.org/10.2130/jjesp.35.23

Yang, M. M. (1994). Gifts, Favors, and Banquets: The Art of Social Relationships in China. Cornell University Press.

Yeganeh, H. (2014). Culture and corruption: A concurrent application of Hofstede's, Schwartz's and Inglehart's frameworks. International Journal of Development Issues, 13(1), 2-24. https://doi.org/10.1108/IJDI-04-2013-0038

Yonhap News. (2018, February 8). (LEAD) Prosecutors raid Hana Bank over allegations of irregular hiring. Yonhap News Agency. Retrieved from http://english.yonhapnews.co.kr/national/2018/02/08/03020 00000AEN20180208003551315.html

Zheng, X., Ghoul, S. E., Guedhami, O., \& Kwok, C. C. Y. (2013). Collectivism and corruption in bank lending. Journal of International Business Studies, 44(4), 363-390. https://doi.org/10.1057/jibs.2013.19 


\section{Appendix}

Appendix Table A. List of Countries with Data

\begin{tabular}{|c|c|c|c|c|c|c|}
\hline Country & GLOBE & $\begin{array}{l}\text { Hofstede } \\
\text { (4) }\end{array}$ & $\begin{array}{l}\text { Hofstede } \\
\text { (LTO) }\end{array}$ & $\begin{array}{l}\text { Hofstede } \\
\text { (IVR) }\end{array}$ & WVS Trust & OECD \\
\hline Albania & $\mathrm{X}$ & & $\mathrm{X}$ & $\mathrm{X}$ & $\mathrm{X}$ & \\
\hline Algeria & & & $\mathrm{X}$ & $\mathrm{X}$ & $\mathrm{X}$ & \\
\hline Argentina & $\mathrm{X}$ & $\mathrm{X}$ & $\mathrm{X}$ & $\mathrm{X}$ & $\mathrm{X}$ & \\
\hline Armenia & & & $\mathrm{X}$ & & $\mathrm{X}$ & \\
\hline Australia & $\mathrm{X}$ & $\mathrm{X}$ & $\mathrm{X}$ & $\mathrm{X}$ & $\mathrm{X}$ & $\mathrm{X}$ \\
\hline Austria & $\mathrm{X}$ & $\mathrm{X}$ & $\mathrm{X}$ & $\mathrm{X}$ & $\mathrm{X}$ & $\mathrm{X}$ \\
\hline Azerbaijan & & & $\mathrm{X}$ & $\mathrm{X}$ & $\mathrm{X}$ & \\
\hline Bangladesh & & $\mathrm{X}$ & $\mathrm{X}$ & $\mathrm{X}$ & $\mathrm{X}$ & \\
\hline Belgium & & $\mathrm{X}$ & $\mathrm{X}$ & $\mathrm{X}$ & $\mathrm{X}$ & $\mathrm{X}$ \\
\hline Brazil & $\mathrm{X}$ & $\mathrm{X}$ & $\mathrm{X}$ & $\mathrm{X}$ & $\mathrm{X}$ & \\
\hline Bulgaria & & $\mathrm{X}$ & $\mathrm{X}$ & $\mathrm{X}$ & $\mathrm{X}$ & \\
\hline Canada & $\mathrm{X}$ & $\mathrm{X}$ & $\mathrm{X}$ & $\mathrm{X}$ & $\mathrm{X}$ & $\mathrm{X}$ \\
\hline Chile & & $\mathrm{X}$ & $\mathrm{X}$ & $\mathrm{X}$ & $\mathrm{X}$ & $\mathrm{X}$ \\
\hline China & $\mathrm{X}$ & $\mathrm{X}$ & $\mathrm{X}$ & $\mathrm{X}$ & $\mathrm{X}$ & \\
\hline Colombia & $\mathrm{X}$ & $\mathrm{X}$ & $\mathrm{X}$ & $\mathrm{X}$ & $\mathrm{X}$ & $\mathrm{X}$ \\
\hline Costa Rica & $\mathrm{X}$ & $\mathrm{X}$ & & & & \\
\hline Croatia & & $\mathrm{X}$ & $\mathrm{X}$ & $\mathrm{X}$ & $\mathrm{X}$ & \\
\hline Cyprus & & & & $\mathrm{X}$ & $\mathrm{X}$ & \\
\hline Czech Republic & $\mathrm{X}$ & & & & $\mathrm{X}$ & $\mathrm{X}$ \\
\hline Denmark & $\mathrm{X}$ & $\mathrm{X}$ & $\mathrm{X}$ & $\mathrm{X}$ & $\mathrm{X}$ & $\mathrm{X}$ \\
\hline Dominican Republic & & & $\mathrm{X}$ & $\mathrm{X}$ & $\mathrm{X}$ & \\
\hline Ecuador & $\mathrm{X}$ & $\mathrm{X}$ & & & $\mathrm{X}$ & \\
\hline Egypt & $\mathrm{X}$ & & $\mathrm{X}$ & $\mathrm{X}$ & $\mathrm{X}$ & \\
\hline El Salvador & $\mathrm{X}$ & $\mathrm{X}$ & $\mathrm{X}$ & $\mathrm{X}$ & $\mathrm{X}$ & \\
\hline Estonia & & $\mathrm{X}$ & $\mathrm{X}$ & $\mathrm{X}$ & $\mathrm{X}$ & $\mathrm{X}$ \\
\hline Ethiopia & & & & $\mathrm{X}$ & $\mathrm{X}$ & \\
\hline Finland & $\mathrm{X}$ & $\mathrm{X}$ & $\mathrm{X}$ & $\mathrm{X}$ & $\mathrm{X}$ & $\mathrm{X}$ \\
\hline France & $\mathrm{X}$ & $\mathrm{X}$ & $\mathrm{X}$ & $\mathrm{X}$ & $\mathrm{X}$ & $\mathrm{X}$ \\
\hline Georgia & $\mathrm{X}$ & & $\mathrm{X}$ & $\mathrm{X}$ & $\mathrm{X}$ & \\
\hline Germany & $\mathrm{X}$ & $\mathrm{X}$ & $\mathrm{X}$ & $\mathrm{X}$ & $\mathrm{X}$ & $\mathrm{X}$ \\
\hline Ghana & & & $\mathrm{X}$ & $\mathrm{X}$ & $\mathrm{X}$ & \\
\hline Greece & $\mathrm{X}$ & $\mathrm{X}$ & $\mathrm{X}$ & $\mathrm{X}$ & $\mathrm{X}$ & $\mathrm{X}$ \\
\hline Guatemala & $\mathrm{X}$ & $\mathrm{X}$ & & & $\mathrm{X}$ & \\
\hline Hong Kong & $\mathrm{X}$ & $\mathrm{X}$ & $\mathrm{X}$ & $\mathrm{X}$ & $\mathrm{X}$ & \\
\hline Hungary & $\mathrm{X}$ & $\mathrm{X}$ & $\mathrm{X}$ & $\mathrm{X}$ & $\mathrm{X}$ & $\mathrm{X}$ \\
\hline Iceland & & & $\mathrm{X}$ & $\mathrm{X}$ & $\mathrm{X}$ & $\mathrm{X}$ \\
\hline India & $\mathrm{X}$ & $\mathrm{X}$ & $\mathrm{X}$ & $\mathrm{X}$ & $\mathrm{X}$ & \\
\hline Indonesia & $\mathrm{X}$ & $\mathrm{X}$ & $\mathrm{X}$ & $\mathrm{X}$ & $\mathrm{X}$ & \\
\hline Iran & $\mathrm{X}$ & $\mathrm{X}$ & $\mathrm{X}$ & $\mathrm{X}$ & $\mathrm{X}$ & \\
\hline Ireland & $\mathrm{X}$ & $\mathrm{X}$ & $\mathrm{X}$ & $\mathrm{X}$ & $\mathrm{X}$ & $\mathrm{X}$ \\
\hline Israel & $\mathrm{X}$ & $\mathrm{X}$ & $\mathrm{X}$ & & $\mathrm{X}$ & $\mathrm{X}$ \\
\hline Italy & $\mathrm{X}$ & $\mathrm{X}$ & $\mathrm{X}$ & $\mathrm{X}$ & $\mathrm{X}$ & $\mathrm{X}$ \\
\hline Jamaica & & $\mathrm{X}$ & & & & \\
\hline Japan & $\mathrm{X}$ & $\mathrm{X}$ & $\mathrm{X}$ & $\mathrm{X}$ & $\mathrm{X}$ & $\mathrm{X}$ \\
\hline Jordan & & & $\mathrm{X}$ & $\mathrm{X}$ & $\mathrm{X}$ & \\
\hline Kazakhstan & $\mathrm{X}$ & & & & $\mathrm{X}$ & \\
\hline Korea, South & $\mathrm{X}$ & $\mathrm{X}$ & $\mathrm{X}$ & $\mathrm{X}$ & $\mathrm{X}$ & $\mathrm{X}$ \\
\hline Kuwait & $\mathrm{X}$ & & & & $\mathrm{X}$ & \\
\hline Kyrgyzstan & & & $\mathrm{X}$ & $\mathrm{X}$ & $\mathrm{X}$ & \\
\hline Latvia & & $\mathrm{X}$ & $\mathrm{X}$ & $\mathrm{X}$ & $\mathrm{X}$ & $\mathrm{X}$ \\
\hline Lithuania & & $\mathrm{X}$ & $\mathrm{X}$ & $\mathrm{X}$ & $\mathrm{X}$ & $\mathrm{X}$ \\
\hline Luxembourg & & $\mathrm{X}$ & $\mathrm{X}$ & $\mathrm{X}$ & $\mathrm{X}$ & $\mathrm{X}$ \\
\hline Malaysia & $\mathrm{X}$ & $\mathrm{X}$ & $\mathrm{X}$ & $\mathrm{X}$ & $\mathrm{X}$ & \\
\hline Mali & & & $\mathrm{X}$ & $\mathrm{X}$ & $\mathrm{X}$ & \\
\hline Malta & & $\mathrm{X}$ & $\mathrm{X}$ & $\mathrm{X}$ & $\mathrm{X}$ & \\
\hline Mexico & $\mathrm{X}$ & $\mathrm{X}$ & $\mathrm{X}$ & $\mathrm{X}$ & $\mathrm{X}$ & $\mathrm{X}$ \\
\hline
\end{tabular}




\begin{tabular}{|c|c|c|c|c|c|c|}
\hline Moldova & & & $\mathrm{X}$ & $\mathrm{X}$ & $\mathrm{X}$ & \\
\hline Montenegro & & & $\mathrm{X}$ & $\mathrm{X}$ & $\mathrm{X}$ & \\
\hline Morocco & $\mathrm{X}$ & $\mathrm{X}$ & $\mathrm{X}$ & $\mathrm{X}$ & $\mathrm{X}$ & \\
\hline Namibia & $\mathrm{X}$ & & & & & \\
\hline Netherlands & $\mathrm{X}$ & $\mathrm{X}$ & $\mathrm{X}$ & $\mathrm{X}$ & $\mathrm{X}$ & $\mathrm{X}$ \\
\hline New Zealand & $\mathrm{X}$ & $\mathrm{X}$ & $\mathrm{X}$ & $\mathrm{X}$ & $\mathrm{X}$ & $\mathrm{X}$ \\
\hline Nigeria & $\mathrm{X}$ & & $\mathrm{X}$ & $\mathrm{X}$ & $\mathrm{X}$ & \\
\hline Norway & & $\mathrm{X}$ & $\mathrm{X}$ & $\mathrm{X}$ & $\mathrm{X}$ & $\mathrm{X}$ \\
\hline Pakistan & & $\mathrm{X}$ & $\mathrm{X}$ & $\mathrm{X}$ & $\mathrm{X}$ & \\
\hline Panama & & $\mathrm{X}$ & & & & \\
\hline Peru & & $\mathrm{X}$ & $\mathrm{X}$ & $\mathrm{X}$ & $\mathrm{X}$ & \\
\hline Philippines & $\mathrm{X}$ & $\mathrm{X}$ & $\mathrm{X}$ & $\mathrm{X}$ & $\mathrm{X}$ & \\
\hline Poland & $\mathrm{X}$ & $\mathrm{X}$ & $\mathrm{X}$ & $\mathrm{X}$ & $\mathrm{X}$ & $\mathrm{X}$ \\
\hline Portugal & $\mathrm{X}$ & $\mathrm{X}$ & $\mathrm{X}$ & $\mathrm{X}$ & $\mathrm{X}$ & $\mathrm{X}$ \\
\hline Qatar & $\mathrm{X}$ & & & & $\mathrm{X}$ & \\
\hline Romania & & $\mathrm{X}$ & $\mathrm{X}$ & $\mathrm{X}$ & $\mathrm{X}$ & \\
\hline Russia & $\mathrm{X}$ & $\mathrm{X}$ & $\mathrm{X}$ & $\mathrm{X}$ & $\mathrm{X}$ & \\
\hline Rwanda & & & $\mathrm{X}$ & $\mathrm{X}$ & $\mathrm{X}$ & \\
\hline Saudi Arabia & & & $\mathrm{X}$ & $\mathrm{X}$ & $\mathrm{X}$ & \\
\hline Serbia & & $\mathrm{X}$ & $\mathrm{X}$ & $\mathrm{X}$ & $\mathrm{X}$ & \\
\hline Singapore & $\mathrm{X}$ & $\mathrm{X}$ & $\mathrm{X}$ & $\mathrm{X}$ & $\mathrm{X}$ & \\
\hline Slovak Republic & & $\mathrm{X}$ & $\mathrm{X}$ & $\mathrm{X}$ & $\mathrm{X}$ & $\mathrm{X}$ \\
\hline Slovenia & $\mathrm{X}$ & $\mathrm{X}$ & $\mathrm{X}$ & $\mathrm{X}$ & $\mathrm{X}$ & $\mathrm{X}$ \\
\hline South Africa & $\mathrm{X}$ & $\mathrm{X}$ & $\mathrm{X}$ & $\mathrm{X}$ & $\mathrm{X}$ & \\
\hline Spain & $\mathrm{X}$ & $\mathrm{X}$ & $\mathrm{X}$ & $\mathrm{X}$ & $\mathrm{X}$ & $\mathrm{X}$ \\
\hline Sweden & $\mathrm{X}$ & $\mathrm{X}$ & $\mathrm{X}$ & $\mathrm{X}$ & $\mathrm{X}$ & $\mathrm{X}$ \\
\hline Switzerland & $\mathrm{X}$ & $\mathrm{X}$ & $\mathrm{X}$ & $\mathrm{X}$ & $\mathrm{X}$ & $\mathrm{X}$ \\
\hline Taiwan & $\mathrm{X}$ & $\mathrm{X}$ & $\mathrm{X}$ & $\mathrm{X}$ & $\mathrm{X}$ & \\
\hline Tanzania & & & $\mathrm{X}$ & $\mathrm{X}$ & $\mathrm{X}$ & \\
\hline Thailand & $\mathrm{X}$ & $\mathrm{X}$ & $\mathrm{X}$ & $\mathrm{X}$ & $\mathrm{X}$ & \\
\hline Trinidad and Tobago & & $\mathrm{X}$ & $\mathrm{X}$ & $\mathrm{X}$ & $\mathrm{X}$ & \\
\hline Turkey & $\mathrm{X}$ & $\mathrm{X}$ & $\mathrm{X}$ & $\mathrm{X}$ & $\mathrm{X}$ & $\mathrm{X}$ \\
\hline Uganda & & & $\mathrm{X}$ & $\mathrm{X}$ & $\mathrm{X}$ & \\
\hline Ukraine & & & $\mathrm{X}$ & $\mathrm{X}$ & $\mathrm{X}$ & \\
\hline United Kingdom & & $\mathrm{X}$ & $\mathrm{X}$ & $\mathrm{X}$ & $\mathrm{X}$ & $\mathrm{X}$ \\
\hline United States of America & $\mathrm{X}$ & $\mathrm{X}$ & $\mathrm{X}$ & $\mathrm{X}$ & $\mathrm{X}$ & $\mathrm{X}$ \\
\hline Uruguay & & $\mathrm{X}$ & $\mathrm{X}$ & $\mathrm{X}$ & $\mathrm{X}$ & \\
\hline Venezuela & $\mathrm{X}$ & $\mathrm{X}$ & $\mathrm{X}$ & $\mathrm{X}$ & $\mathrm{X}$ & \\
\hline Vietnam & & $\mathrm{X}$ & $\mathrm{X}$ & $\mathrm{X}$ & $\mathrm{X}$ & \\
\hline Zambia & $\mathrm{X}$ & & $\mathrm{X}$ & $\mathrm{X}$ & $\mathrm{X}$ & \\
\hline Zimbabwe & $\mathrm{X}$ & & $\mathrm{X}$ & $\mathrm{X}$ & $\mathrm{X}$ & \\
\hline
\end{tabular}

Appendix Table B. Additional Information About the Sample

\section{Dataset}

The Global

Competitiveness Report

2017-2018

Hofstede's National Culture Dimensions

\section{Information}

Data on all the countries' indicators for favoritism and nepotism/cronyism can be publicly found and accessed at the World Economic Forum:

https://www.weforum.org/reports/the-global-competitiveness-report-2017-2018

The most recent version of the National Culture Dimensions data can be publicly found and accessed here: https://geerthofstede.com/research-and-vsm/dimensiondata-matrix/

Individualism-collectivism dimension was reverse scored to get the collectivism variable. Three cultures (Canada, Germany, and Switzerland) were weighted and/or 
averaged based on demographic splits. South Africa's collectivism and uncertainty avoidance dimensions were from White samples only.

GLOBE's Cultural

Orientations

Taiwan

As Taiwan is not recognized as a formal, sovereign country, World Bank did not have data on Taiwan's GDP per capita. This data was obtained from the International Monetary Fund (2017). 